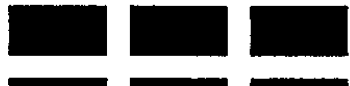 \\ THE WILLIAM DAVIDSON INSTITUTE \\ AT THE UNIVERSITY OF MICHIGAN BUSINESS SCHOOL
}

\section{Which Enterprises (Believe They) Have Soft Budgets after Mass Privatization? Evidence from Mongolia}

by James Anderson, Georges Korsun, and Peter Murrell

Working Paper Number 83

October 1997

\section{The Davidson Institute Working Paper Series}

\author{
The Davidson Institute \\ 701 Tappan Street \\ Ann Arbor, MI 48109-1234 USA \\ Tel. (734) 763-5020 \\ Fax (734) $763-5850$ \\ wdi@umich.edu \\ http://www.wdi.bus.umich.edu
}

Copyright James Anderson, Georges Korsun, and Peter Murrell, 1997. Disseminated by the Davidson Institute with permission of the authors. 


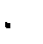




\title{
Which Enterprises (Believe They) Have Soft Budgets after Mass Privatization? Evidence from Mongolia
}

\author{
James Anderson, Georges Korsun, and Peter Murrell* \\ Department of Economics and IRIS Center \\ University of Maryland \\ College Park \\ MD 20742 \\ USA \\ email: murrell@econ.umd.edu
}

\footnotetext{
"The current affiliation of Korsun is Chemonics International. We thank William Evans and Robert Schwab for invaluable discussions and computer programs, Berta Heybey for research assistance, Batbold, Bathoyag, and Bailyhuu for generous help and advice; Gunpilmaa for translation and secretarial work; and the teams of researchers and accountants for collecting information with care and precision: Otgonchimeg and T. Batjargal, the team leaders, and Badarch, Batbold, Erdenesanaa, Gansuh, Ganzorig, Namsrai. Tungalag, Altansuh, D. Batjargal, Bayasgalan, Davaasuren, Hishigsuren, Idshinrinchin, Jigden, Lutdorj, Norjii, Nyamsuren and Tseesuren. We are indebted to the directors of some 250 Mongolian enterprises for their cooperation. We gratefully acknowledge the support of the World Bank and of the U.S. Agency for International Development under Cooperative Agreement No. DHR-0015-A-00-0031-00 to the Center on Institutional Reform and the Informal Sector (IRIS). The findings, interpretations, and conclusions expressed in this paper are entirely those of the authors. They do not necessarily represent the views of the World Bank, its Executive Directors, or the countries they represent.
} 


\begin{abstract}
Which Enterprises (Believe They) Have Soft-budgets after Mass Privatization? Evidence from Mongolia"

To ascertain the prevalence of soft budgets and to find causes of softness, we surveyed 251 privatized Mongolian enterprises, asking whether state aid was expected when financial difficulties arose. Onequarter of the enterprises expected such soft-budget aid, a large proportion of which have central government ownership. We examine causes of soft budgets in addition to state ownership, but the state variable dominates. Results are robust when using either instrumental variables or bivariate probit to unmask unmeasured selection effects. Local government ownership has a much weaker effect than does central ownership.
\end{abstract}

Journal of Economic Literature Classification Numbers: P1 1, P21, O53, H70, H20. 


\section{Introduction}

Reducing the prevalence of soft budgets is a primary aim of post-socialist economic reforms. While budget constraints have certainly hardened in the 1990's (Pinto et al 1993, Kornai 1993, and Fan and Schaffer, 1993), this process is far from complete (Belka et al 1994; Alfandari, Fan, and Freinkman, 1996; Earle, Estrin, and Leshchenko 1996.) Thus, it remains of considerable significance to ask what proportion of enterprises have soft budgets, the degree to which constraints are soft, and which types of enterprises have soft budget constraints. Answering these questions provides insight into the progress of reforms and addresses the fundamental problem of finding the ultimate cause of soft budgets. ${ }^{1}$

The usual approach in the empirical examination of soft budgets is to observe whether enterprises receive subsidies or other state aid. But this approach has three drawbacks. First, sources of state aid are myriad, making it difficult to account for them all. Second, the presence of subsidies is not synonymous with the existence of a soft budget if one uses Kornai's (1980) classic definition that a soft budget exists when the state is willing to help an enterprise escape the adjustments consequent on financial setbacks. State aid might be unrelated to enterprise performance (Kornai, 1992a p. 10) Third, an enterprise that is not in financial difficulties might receive little state help, but nevertheless might be acting under the premise that such help would be forthcoming were fortunes to change. Such an enterprise does have a soft budget and might, as a consequence, behave in an imprudent manner causing large inefficiencies.

An alternative approach is to survey managers on whether they believe that their enterprises face soft budgets. This approach does not require examining specific government policies, nor does it associate soft budgets with current aid only. Such a survey can reveal the proportion of enterprises expecting government help in times of trouble. Of course asking enterprise officials directly about soft budgets has its disadvantages too, primarily those associated with the validity of survey evidence concerning expectations rather than facts. Nevertheless, given the weak empirical information available

\footnotetext{
1. See Dewatripoint and Maskin (1995), Kornai (1980), Qian and Roland (1996), and Shleifer and Vishny (1994) for important contributions to the theory of soft budgets.
} 
concerning the causes of soft budgets, survey evidence of a new kind carries the potential of offering significant new insights.

To collect the evidence used in this study, we surveyed in mid-1996 251 large privatized enterprises in Mongolia, over half of the enterprises that had passed through the 1991-5 mass privatization program for large enterprises. ${ }^{2}$ Of course, Mongolia itself does not have the significance of a Russia or a Poland. But it does provide a case study whose results are of much wider applicability than simply descriptive of this small central Asian country. Since Mongolia is a fairly typical poorer reforming socialist country, results for this country are of general relevance for understanding the transition process.

One of the questions on the survey elicited expectations of whether and to what degree the state would come to an enterprise's aid if that enterprise fell upon hard times, asking what proportion of lost revenues the state would make up if losses threatened the enterprise's ability to maintain its employment level. The question is reproduced in its entirety in Table 1, which summarizes enterprise responses. In phrasing the question, we focused on employment as the goal of soft budgets, to remove any negative connotations that respondents might feel in revealing the existence of state handouts. Employment maintenance is a likely goal of governments in transition countries and it is a goal that would be seen as positive by an overwhelming majority of the Mongolian populace. ${ }^{3}$

Table 1 reflects the responses of 249 enterprises, 109 of which had residual state ownership. As Table 1 clearly shows, the perceived degree of softness is strongly related to the amount of state ownership and to whether the central or local government owns the state shares. In fact, as we show in

\footnotetext{
2. The survey covered all privatized enterprises in the national capital. Ulaanbaatar, plus those in the regional centers of eight of the remaining twenty-one administrative districts of the country. The survey collected both qualitative information, from general directors using a survey containing close-ended questions, and quantitative accounting information. The response rate for the survey was above $99 \%$. The relatively more cumbersome logistical requirements for collecting detailed accounting information led to a research design with a $10 \%$ smaller sample of enterprises for the collection of accounting information than for the qualitative information.

3. To remove any ethical content from the answers, the question used "unfortunate market conditions" as the cause of the enterprise's problems, rather than any wording that could have been taken to imply that the enterprise was responsible for its plight.
} 
this paper, the degree of softness varies with little else. Thus, the pivotal results of the paper are already captured in Table 1: the level of central government ownership matters a great deal in expectations of soft budgets and the level of local government ownership matters much less.

Of course, Table 1 is no more than suggestive. It tells us nothing about levels of statistical significance or of the effects of omitted variables. Moreover, the patterns in Table 1 could simply reflect the selection of enterprises into state ownership, where the characteristics of enterprises with residual state ownership are exactly those characteristics that lead to soft budgets, independently of ownership. However, when we address these issues in the remaining sections of this paper, the message of Table 1 is resoundingly endorsed.

The analysis begins in Section II, which provides the background on Mongolia necessary to interpret the results and to suggest variables omitted from Table 1. Section III uses ordered probit to examine the causes of soft budgets in a single-equation framework, introducing the omitted variables suggested by existing theory as well as by the features of Mongolia.

Section IV examines the vexing issue of selection: are unobserved characteristics of state enterprises responsible for soft budgets, rather than state ownership itself? Two different approaches are taken to investigate selection effects, based on different simplifying assumptions. First, we ignore the categorical and censored nature of the dependent variable and use linear instrumental variables. Second, we reduce the variables of direct interest to binary response variables and estimate a bivariate probit model. The results suggest that the effect of central government ownership is stronger once selection effects are taken into account. 


\section{Background: Mongolian Reforms and Government ${ }^{4}$}

In 1990, a peaceful revolution in Mongolia led to sweeping reforms. The movement to democracy was swift and apparently irreversible. After an election in mid-1990, a broad coalition government was formed in which the old communist party, the Mongolian People's Revolutionary Party (MPRP), was dominant. The economics portfolio was held by a member of one of the new parties, the National Progress Party, which had been formed by a group of young economists who were convinced that the country needed radical reforms. The first two years of democracy saw very strong economic reform.

An election in 1992 gave the MPRP an overwhelming majority in parliament. The new parties left the coalition and the MPRP governed alone for the next four years. During this time, economic reforms proceeded less swiftly, but the general direction of reform was clear. So, too, was the cementing of political reforms, which was underscored by the election of a non-MPRP president in 1993 and the surprise election victory in 1996 of the Democratic Union, a coalition of new parties.

The data presented in this paper reflect the circumstances immediately before the 1996 election. This was the end of a period (1992-6) in which the government had been more conservative than its predecessor, which had instituted the mass privatization program during 1990-2. These temporal changes in the reform orientation government are exactly those most suited to an examination of . prominent theories of privatization. In those theories, a reformist government undertakes privatization in order to change the incentives of subsequent governments, which might otherwise be prone to intervention. Observing the actions of the later more conservative governments affords the opportunity to observe whether private ownership really does provide the binding effect sought by the reformers.

Mongolian economic reforms during 1991-1996 were characterized by ebbs and flows that have been so typical of reforming countries. Formal liberalization of the economy was announced very early,

\footnotetext{
4. This section provides only the information necessary for an understanding of the general context in which the paper's results should be placed. For further detail, see Boone (1994) on stabilization, Murrell, Dunn, and Korsun (1996) on price liberalization, and Korsun and Murrell (1995) on privatization.
} 
but actual liberalization proceeded more slowly, due to the effects of lingering interventions. By the end of 1993, despite the failure of initial attempts at stabilization, runaway inflation no longer appeared to be a danger. Nevertheless, since that time successive governments have struggled to maintain fiscal balance and monetary control, inflation remaining above $50 \%$ in 1995 and 1996 . Growth resumed in mid-1993, after a relatively mild (for transition countries) fall in GDP of $20 \%$. Concurrent with the fall in GDP, there was a catastrophic drop in living standards as a result of the withdrawal of Soviet aid, which during the 1980 's had been as high as $30 \%$ of Mongolian GDP.

The centerpiece of the early economic reforms was privatization, which occurred in three different programs, for small enterprises, for large enterprises, and in agriculture. Our data reflect the circumstances of the enterprises that passed through the large privatization program beginning in March 1992. In the next four years, 483 large enterprises were privatized in the voucher, mass-privatization program: $55 \%$ in $1992,30 \%$ in $1993,12 \%$ in 1994 , and $3 \%$ in 1995.

Enterprises had little scope for decision-making during privatization. All large enterprises went through the same privatization process: preparation of a plan, including a pre-announced residual state share, corporatization, then the selling of shares on the stock exchange, not for cash but for vouchers that had been issued to every citizen. Markets, in which vouchers were exchanged for shares, determined the allocation of enterprise shares among individuals. Of enterprises passing through the mass privatization process, $45 \%$ had lingering state ownership. In the sample of enterprises studied in this paper, the state ownership share averages $20.4 \%$, insiders and their families own $35 \%$, and outsiders $45 \%$.

In Mongolia, as in many other transition countries, insider owners find it easier to gain representation on corporate bodies than do non-state outsiders. On the one hand, insider shareholding probably resulted from concerted efforts on the part of employees to hold a large share in their own enterprises. On the other, outsiders had few mechanisms to create blocks of shares. Investment funds are not of any significance. Vouchers were non-tradeable, so that initial share ownership was diffuse. 
The secondary trading of shares officially began only in August 1995, ten months before our data was collected. As a result, by mid-1996, only thirteen percent of enterprises reported any presence on their boards of individuals representing investment funds or large outsider shareholders.

An important element of this paper's results lies in differentiating between the actions of central and local government. Therefore some brief comments on the structure of government are appropriate. Mongolia is a unitary state. ${ }^{5}$ Twenty-two regional entities lie immediately below the central government (21 aimags, or provinces, and the capital city.) Local representative assemblies are elected. Local executives, or governors, are appointed by the central government for four year terms on the nomination of the local assemblies.

Borrowing authority and the use of the most important tax instruments are reserved for central government. Localities do have the use of personal income taxes, fees for the use of natural resources, real estate taxes, and a variety of other lesser taxes, but tax rates and tax policy are set by the center. The governors are responsible for allocating the local budget to different uses and have a considerable degree of flexibility in that decision. They are also responsible for administering the state ownership share in those enterprises assigned to their locality's stewardship.

The formal authority of local governments is heavily circumscribed by the central government, echoing the country's origins in a highly centralized communist state. However, localities have more discretion than suggested by the highly centralized state structure, as a result of the decreased willingness and the declining capacity of the central government to exercise the degree of control that it formally possesses. With the formal rules incompletely specified, sometimes contradictory, and undergoing rapid change, the degree of discretion held and exercised by any particular local government is highly dependent on the personal skills and relationships of the governor.

\footnotetext{
5. On the subject matter of the ensuing paragraphs, see Enkhbat (1993), Government of Mongolia (1993), Government of Mongolia (1995), and State Statistical Office of Mongolia (1996).
} 
These background notes end with terminology. We use the designation "centrally owned enterprise" to designate an enterprise that has residual state ownership that is administered by the central government. The designation "locally owned" is analogously defined, as are the terms central and local ownership. Note, however, that the difference between these two types of enterprises does not lie in ownership per se, but rather in which level of government administers that ownership. ${ }^{6}$

\section{Searching for Omitted Variables}

In the present section, we use existing theory and knowledge of the peculiar characteristics of Mongolia to suggest and test variables that might help to explain the existence of soft budgets. The focus is not on these variables themselves but rather on whether the relationships suggested by Table 1 still hold once such variables are introduced.

There is an extensive theoretical literature on why state ownership leads to soft budgets. Kornai (1980) provides the seminal analysis suggesting that state paternalism provides the important causal link. Shleifer and Vishny (1994) and Boycko, Shleifer, and Vishny (1996) focus on the politicians' objectives of maintaining employment, showing that pursuit of this objective is linked to state ownership when the political cost of subsidizing employment through direct grants is higher than the cost of forgoing the state's share of enterprise profits. These theories, as well as much historical experience, provide compelling reasons to include state ownership as the pivotal variable in our empirical analysis. The theories also predict that the degree of soft-budgets varies with the amount of state ownership, providing the justification for the use of a continuous state ownership variable rather than a binary one.

\footnotetext{
6. The terms are introduced for parsimony only and do not reflect de jure ownership rights, which have remained ill-defined throughout the reform era: retained enterprise shares have been simply classified as state-owned without any formal designation of which state agency is the legal owner. The terms centrally owned and locally owned do however accurately reflect de facto usage rights, which have become cemented through time in informal arrangements.
} 


\section{1 Local and Central Ownership}

There is less received theory and evidence on how the importance of state ownership varies across levels of government. Oates and Schwab (1988) show that inter-jurisdictional competition between local governments will weed out inefficient policies. Shleifer and Vishny (1994) argue that the line between state ownership and soft budgets is weakened when the government's own fiscal constraint is tighter, implying that local governments will usually impose harder budget constraints. In China, this has certainly been the case (Qian and Xu, 1993.) Qian and Roland (1996b) establish a direct link between governmental decentralization and harder budget constraints by showing that inter-regional competition for capital raises the cost of subsidies and reduces the incentive for bailouts.

In Mongolia local governments have little room for fiscal maneuver, while the central government possesses the tools of a sovereign state. In addition, the local governments face inter-jurisdictional competition, as regional shares of national markets shift and as new enterprises choose between localities. Hence, one would predict that local government ownership would be far less important a determinant of soft budgets than would central government ownership.

We therefore use two separate ownership variables in our analysis: $C e n o_{\mathrm{i}}$ is the percentage central ownership of enterprise $\mathrm{i}$ and $\mathrm{Loco}_{\mathrm{i}}$ is the percentage local ownership. Definitions of variables and descriptive statistics appear in Table 2.

Given the nature of the question reported in Table 1, ordered probit is the natural tool to relate softbudget scores to their determinants. Suppose that $Y_{i}^{*}$ is a continuous latent variable reflecting the degree of softness of the budget constraint of enterprise i. Then:

$$
\mathrm{Y}_{\mathrm{i}}^{*}=\mathrm{X}_{\mathrm{i}} \beta+\text { Ceno }_{\mathrm{i}} \delta+\operatorname{Loco}_{\mathrm{i}} \gamma+\epsilon_{\mathrm{i}}
$$

where $X_{i}$ is a vector of observations on other pertinent enterprise characteristics, $\beta, \gamma$, and $\delta$ are parameters, and $\epsilon_{\mathrm{i}}$ represents relevant unobservable enterprise characteristics. Then, if $S o t_{\mathrm{i}}$ is the 
response of enterprise $\mathrm{i}$ on the soft budget survey question $\left(S o f t_{\mathrm{i}}=0,1, \ldots, 10\right)$, Soft is related to $\mathrm{Y}_{\mathrm{i}}^{*}$ in the following manner:

$$
\begin{aligned}
& \text { if } Y_{i}^{*} \leq \alpha_{0} \text {, then } \text { Soft }_{\mathrm{i}}=0 ; \\
& \text { if } \alpha_{j-1}<Y_{\mathrm{i}}^{*} \leq \alpha_{\mathrm{j}} \text {, then } \text { Soft }_{\mathrm{i}}=\mathrm{j} ; \text { for } \mathrm{j}=1, \ldots, 9 ; \text { and } \\
& \text { if } \alpha_{9}<\mathrm{Y}_{\mathrm{i}}^{*} \text {, then } \text { Soft }_{\mathrm{i}}=10, \\
& \text { with } \alpha_{0}<\ldots<\alpha_{9} \text { parameters. }
\end{aligned}
$$

We estimate the parameters $\alpha_{0}, \ldots, \alpha_{9}, \beta, \gamma$, and $\delta$ by ordered probit. The working assumption at this stage is that all non-state-ownership determinants of soft budgets are included in the vector $\mathrm{X}_{\mathrm{i}}$ so that $C e n o_{i}$ and $\mathrm{Loco}_{\mathrm{i}}$ are uncorrelated with $\epsilon_{\mathrm{i}}$. In Section IV, we relax this assumption.

The first results appear in Table 3, column 1 containing the ordered probit regression when only state ownership variables are included. For reasons of brevity, we omit the estimates of the ten intercept terms (the $\alpha_{j}$ ). ${ }^{7}$ However, the size of $\gamma$ and $\delta$ relative to the magnitude of the intercept terms gives important information on the strength of the ownership effect. We provide this information in Table 3 in summary form. The estimated value Cen50 shows the increase in percentage central ownership that would change the degree of softness of the budget constraint by $50 \%$, from a value of Soft that is on the borderline between 0 and 1 to a value that is on the borderline between a score of five and six. Loc50 is analogously defined for the local ownership variable.

This first regression solidifies the impressions from Table 1. Central ownership is highly significant and local ownership is of weak significance. A change of central ownership of $52 \%$ would lead to a "50\% softening" of the budget constraint, while even complete local ownership would not lead to this degree of softness.

\footnotetext{
7. These terms are always significant at conventional levels of significance.
} 
In the ensuing sub-sections, we examine non-state-ownership variables in two different forms of the ordered probit. First, each variable is added singly to the regression (columns 2-10 of Table 3) and then all variables are entered into a single regression (column 11.) The focus is not on testing the significance of these individual variables, but rather on whether inclusion of such variables alters the perceptions of the effects of the state variables.

\section{III.2 Insiders and Outsiders.}

Shleifer and Vishny (1994) and Boycko, Shleifer, and Vishny (1996) argue that soft budgets are more likely to arise when the tastes of owners are more similar to those of the government: insider ownership is more likely to lead to soft budgets than is outsider ownership. Earle and Estrin (1996, pp. 208-9) also emphasize the greater likelihood of soft budgets with insider ownership. Li (1996) theorizes that soft budget constraints arise when insiders have greater control rights than those formally bestowed by ownership. Since insiders face loss of human capital when an enterprise is in trouble, they will be more likely to continue unsuccessful projects than would the outsider who is supplying finance. To examine these theories, we use the variable Inso, the percentage of the firm owned by insiders.

Given the identity relationship among the various forms of ownership (Ceno + Loco + Inso $=$ 100 - outsider ownership) and the fact that outsider ownership is the omitted ownership variable, the coefficient on an included ownership variable measures the effect of increasing the value of the included variable while decreasing outsider ownership. The results in column 3 suggest that an exchange of ownership between insiders and outsiders makes little difference to soft budgets, while an exchange between the private sector and the central government has a large effect.

Because it is difficult for outsider owners in Mongolia to effect concerted action, many outsider owners will be passive. This suggests focusing on those outsiders who have been able to exert an influence on governance. The survey collected data on which enterprise boards included individuals representing either investment funds or large outsider shareholders, which are the best data available on 
$-11-$

when outsiders have some potential to affect corporate activities. The dummy variable Outbrd reflects these data. The inclusion of this variable does not suggest revising any previous observations.

\section{III.3 Soft-budgets as Redistribution}

In Kornai's original formulation, soft budgets are seen primarily as a means of allowing enterprises to escape adjustments that would otherwise result from financial exigencies. This is the view that stimulated the precise wording in the question used to generate Soft. Given this wording there is no essential reason why Soft should reflect the present financial circumstances of the enterprise.

Nevertheless, memories can be short and an enterprise that is currently in difficult circumstances might have a clearer memory of soft budgets. In order to examine whether this is the case, we included current profits (Prof) in the regression. A simple measure of profits might be unsatisfactory, however, because potential profits might well be paid as excess wages in insider controlled firms. This suggests using value-added per employee ( $\mathrm{Vapl}$ ). The inclusion of these variables (columns 4,5, and 11) does not add any information. Less profitable or less productive enterprises do not seem to perceive soft budgets any more strongly than other enterprises.

\section{4 Too Big to Fail}

Kornai (1992b, p. 143) suggests that larger enterprises have softer budgets. Given the difficulties of collective action across enterprises and the relative ease of mobilizing a large number of workers in a single enterprise, large enterprises will usually have political power disproportionate to their size. This suggests using the number of employees as an explanatory variable (Emp). Moreover, an enterprise of a* given size probably has more power the smaller is the jurisdiction in which it is situated, given the transactions costs of negotiating political deals and the leverage that results from first-past-the-post 
election rules. Hence, we also examine enterprise employment as a share of the local population (Empsh). Neither variable causes a modification in previous conclusions (columns 6, 7, and 11). ${ }^{8}$

There relative importance of the enterprise on the national market might also be pertinent. In a small country such as Mongolia, which is relatively isolated from world markets by geography and by legacies of the communist era, an enterprise that is dominant in its market might well have the political muscle that comes from threatening disruptions. In Mongolia, many large enterprises are important users of agricultural materials, the production of which supports a large share of the population. These enterprises have certainly been willing to exploit their links to the countryside for political advantage.

Independent data on market concentration are not available and we are forced to use survey data. We asked enterprises to estimate their percentage share of the national market. However, there are obvious problems of endogeneity with this variable. State aid might enable an enterprise to gain a larger market share leading to a positive correlation between market share and soft budgets that has little to do with the causes of soft budgets.

To counter this problem, we used the survey data to construct a measure of market share that is exogenous to the enterprise. Each enterprise's major product was given a 2-digit classification. Then for each enterprise in succession, we dropped that enterprise from the data set and ran an ordinary least squares regression of reported market shares on product and regional dummies. Predicted values from this regression were used as a proxy for market share. By its construction, this variable, Mktshp, contains no direct information from the enterprise's report of its own market share.

This market share variable is highly significant (column 8), its presence strengthening the perceived effect of the state ownership variables. This variable measures market power on a national scale,

\footnotetext{
8. Of course, if the level of employment is an effect rather than a cause of soft budgets, the regression will be mis-specified. Note, however, that the employment variable is lagged relative to the soft budget variable (and experiments with further lagging give the same results.) Moreover, it is likely that the coefficient on the employment variables will be biased upwards if there is a problem of endogeneity. suggesting that our conclusion does not suffer from biases due to endogeneity.
} 
$-13-$

something which is presumably much more important for the central government than for local government. Hence, this variable reflects central government policy rather than local policies, which is consistent with previous observations on the relative important of central and local ownership. These results suggest that political power arises more from market muscle than from size of workforce.

\section{III.5 Sectoral and Regional Effects}

Kornai (1992b, p. 143) suggests that priority sectors had soft budgets during the socialist era. Certainly, in Mongolia the processing of agricultural raw materials has particular cachet. Therefore, we examine sectoral effects, for which we use a standard Mongolian seven-sector categorization. For the sake of brevity, we do not report complete results: Table 3 reports the results for only the one sector dummy having a significant coefficient. This sector, the distribution or trade sector (Trade), has a significantly lower propensity to have soft budgets than other sectors when it is added on its own to the regression (column 9) but not when included with all other variables (column 11.)

In a country where democracy is so new and many old officials are still in power, it is plausible that there could be great differences between policies in different localities. Therefore, we constructed regional ownership variables analogous to Loco, measuring the ownership of an enterprise under the control of each of the nine local authorities covered by our sample. Again complete results are not reported, since only one regional ownership variable has a significant coefficient. This variable, Regd, is included in regressions 10 and 11 , where the variable Loco becomes insignificant suggesting that the significance of the local variable in previously reported regressions reflects the policies of just one region. ${ }^{9}$ This region, Darhan, an industrial city, overspent its planned budget in 1995 by $54 \%$, much more than did any other locality (State Statistical Office of Mongolia, 1996, pp. 1-3.) Evidently, the locality itself had a soft budget. We also calculate the value of $\operatorname{Reg} 50$, a variable analogous to Cen 50

\footnotetext{
9. Regional dummies were also examined, in addition to the ones mentioned in the text, which are regional dummies crossed with local ownership. None of the regional dummies were significant suggesting that the ownership component of Regd is crucial.
} 
that measures the effects of an increase in ownership in Darhan. The values of Reg50 and Cen50 are similar in magnitude, indicating that local ownership in this city has an effect that is similar to that of central ownership, in contrast to the smaller effect of ownership in other localities.

\section{III.6 A Summary}

In regression 12, we include all the variables in regressions 1-11 that had significant t-statistics in at least one equation. The sectoral dummy in this regression is no longer significant (as is also the case in regression 11) and is omitted in regression 13, which is the regression that summarizes the results of this search for omitted variables. This summary regression suggests that it is state ownership and little else that determines an enterprise's perceptions of whether it has a soft budget. The result for central ownership is robust across the elements of Table 3. However, the local ownership variable is of marginal significance in the summary regression and is not significant in several other instances. The magnitude of the local ownership effect is half that of central ownership.

\section{Seeking Selection Effects.}

So far, we have taken $\epsilon_{\mathrm{i}}$ to be uncorrelated with the included ownership variables. This is reasonable under the assumption that we have been able to include all pertinent variables in $\mathrm{X}_{\mathrm{i}}$. Although the previous section covers the most plausible hypotheses that suggest elements of $X_{i}$, it is impossible to be sure on an a priori basis that this assumption is correct. If there is an unmeasured determinant of Soft of which we are unaware, then the same variable could also be a determinant of Ceno, leading to bias in the estimates presented in Table 3. In particular, if some unmeasured enterprise characteristic is positively related to both state ownership and soft budget constraints, then one might conclude that there is an ownership effect on soft budgets where none exists.

More formally, our system of equations now comprises (1), (2), and:

$$
\text { Ceno }_{\mathrm{i}}=\mathrm{F}\left(\mathrm{Z}_{i}, \eta_{\mathrm{i}}\right)
$$


$-15-$

where $F($.$) is a function that leads to censoring at 0, Z_{i}$ is a vector of explanatory variables, and $\eta_{i}$ is an error term. (We focus only on central ownership to simplify the presentation.) If all pertinent variables are included in $X_{i}$ in equation (1) and $Z_{i}$ in equation (2), then $\epsilon_{i}$ is independent of $\eta_{i}$ and the estimates in the preceding section are maximum likelihood. However, if there is a variable that actually belongs in $\mathrm{X}_{\mathrm{i}}$ and $Z_{\mathrm{i}}$, but is unmeasured, it is a component of both $\epsilon_{\mathrm{i}}$ and $\eta_{\mathrm{i}}$. Then, Ceno $o_{\mathrm{i}}$ and $\epsilon_{\mathrm{i}}$ are correlated and our previous estimates are inconsistent. The same logic applies also to Loco and Regd.

Combining an 11-category ordered probit with tobit formulations for each of the three state ownership variables presents a formidable challenge for estimation, one which has not been taken up in the existing literature and one which we do not pursue. Rather a pragmatic route is taken, in which two different methods of accounting for selection bias are employed, based on two different sets of simplifying assumptions. In section IV.1, we ignore the censoring of the ownership variables and the categorical character of Soft and use standard linear methods. In section IV.2, we construct binary variables for use in a bivariate probit model. The focus throughout is on examining whether the strong effect of central ownership survives when we introduce the possibility of selection effects.

\section{IV.1 Linear Instrumental Variables}

If one ignores the categorical and censored nature of Soft, then one can estimate the following linear equation using instrumental variables methods:

$$
\operatorname{Soft}_{\mathrm{i}}=\mathrm{X}_{\mathrm{i}} \beta+\operatorname{Ceno}_{\mathrm{i}} \delta+\operatorname{Loco}_{\mathrm{i}} \gamma+\operatorname{Reg}_{\mathrm{i}} \theta+\epsilon_{\mathrm{i}}
$$

Ideally, the pertinent instruments would emerge through a precise understanding of the process that * determined the size of residual state shares during privatization. Unfortunately, this process was not transparent. Decisions on the state share resulted from the interactions of many actors and extensive interviews with the major participants have not served to untangle the objectives and constraints that 
drove the elements of this process. ${ }^{10}$ However, these interviews and a previous statistical study (Korsun and Murrell, 1996) have identified some of the variables that are pertinent: Appdate, the date at which the enterprise's privatization plan was approved, Empp, employment at the time of privatization, and Share, the number of shares in the enterprise at the time of privatization.

Each of these variables has a plausible relation to the size of state ownership. Appdate captures a secular decline in state shares as experience with privatization proceeded. Share was defined as equal to the book value of enterprise net assets at the time of privatization, every enterprise share corresponding to the same amount of assets. Enterprises with larger values of Share were more likely to have residual state ownership perhaps because such enterprises were the largest most prestigious enterprises, which had been built as important state investment projects in the communist era. Empp is negatively related to state ownership, suggesting that the reformist privatizers might have wanted to privatize completely those enterprises facing the biggest restructuring problems.

Additionally, these variables are not current determinants of budgetary softness. Appdate was determined by idiosyncratic features of the privatization process, such as the familiarity that specific privatization officials had with particular enterprises. (To speed the privatization process initially, officials worked first with enterprises they knew well.) Share reflects the book values of the planned era, which are very different from present valuations determined in a completely new economic system, with vastly different relative prices, a new set of trading partners, and new institutions. ${ }^{11}$ Employment in enterprises has changed dramatically over the reform period, the average enterprise shedding over $40 \%$ of its labor force, suggesting that Empp would not be a current determinant of enterprise size. Lastly,

\footnotetext{
10. Indeed, many important participants were not aware of the overall dimensions of residual state share.

11. Were past book values equal to present values each enterprise would have had the same voucher share price during privatization. In fact, the ratio of the highest share price to the lowest was more than 300 .
} 
$-17-$

while it is true that the models of Section III are mis-specified if there are selection effects, the results of that section suggest that even current employment does not belong in $\mathrm{X}_{\mathrm{i}}$.

Table 4 shows the strength of the relation between the instruments and the instrumented variables, listing the R-squareds of regressions of each of the instrumented variables on the instruments. Evidently, this small set of instruments is satisfactory for Ceno, but not for either local variable, Loco and Regd. The factors that explain residual central state ownership do not seem to apply at a local level. ${ }^{12}$ It is of course highly possible that local decisions varied idiosyncratically across regions.

In some of the instrumental variables regression that follow, regional dummies are added to the set of instruments. Regional dummies are related to Loco and Regd because there are variations in the residual state share across regions. Table 4 provides the pertinent evidence on the strength of the relationships.

One might question the validity of regional dummies as instruments, arguing that the prevalence of soft budgets will vary across regions and therefore that regional dummies belong in $X_{i}$. But we have argued that regional variation in soft budgets will make itself felt through the effects of the regionalownership variables, which are included in the pertinent regressions (to the extent suggested by the results of Table 3.) Therefore, the regional dummies themselves are not candidates for inclusion in $X_{i}$ given the use of the regional-ownership variables. Also, it is the case that regional dummies are all insignificant when added to the ordered probit regressions appearing in the last column of Table 3 (although, again, such evidence must be treated with great caution since those regressions are misspecified if there are selection effects.) Finally, we later present results of overidentification tests that endorse the decision to use the regional dummies as instruments.

12. The privatization decisions on locally owned enterprises were usually made by local privatization commissions. 
Table 5 presents the instrumental variable results. Because the case for the use of the regional dummies as instruments is somewhat weaker than that for the other three instruments and because central ownership is the primary variable of interest, we vary the set of instruments used and the variables instrumented across the columns of Table 5. Similarly to Table 3, Table 5 reports the size of the effect of each ownership variable: Cen50, Loc50, and Reg50 measure the increase in ownership that would be required to change a hard budget constraint into one with a $50 \%$ degree of softness. The change in the interpretation of Soft, from an ordered categorical variable to a continuous one, necessitates a change in the method of calculation of these three measures. Now these measures indicate the change in ownership that would change the predicted score on Soft from 0 to 5 , a definition analogous to that used in Table 3.

The results in Table 5 are consistent with those previously presented. Central ownership is consistently significant, while the significance of local ownership depends upon the particular regression estimated. The magnitude of Cen50 is comparable with that in Table 3 . When either of the local ownership variables is instrumented without using the regional dummies (columns 2,3, and 4), both are insignificant. When regional dummies are added to the set of instruments (column 5), Loco is not significant but Regd is, a result that could be due to the differing strength of the two instruments for the two variables, but is also consistent with previous observations that Loco is of marginal importance. Certainly, the estimates of Cen50, Loc50, and Reg50 in column 5 serve to underscore the fact that local ownership in one region, Darhan, has an effect similar in magnitude to that of central ownership, but the effect of local ownership elsewhere is much weaker than that of central ownership.

Finally, if one is willing to accept the use of instrumental variables techniques despite the noncontinuous nature of the dependent variable, then one can formulate tests of whether the instruments are appropriately excluded from the soft-budget equation. The test statistic examines whether overidentifying restrictions are satisfied and is easily calculated from a regression of the estimated residuals of the soft budget equation on all exogenous variables (Newey, 1985, p. 245). Under the null hypothesis 
of exogeneity of all instruments, the statistic has a $\chi^{2}$ distribution with degrees of freedom equal to the number of instruments minus the number of variables presumed to be endogenous in the soft budget regression. The last lines of Table 5 contain the results, which give no reason to doubt the choice of instruments.

\section{IV.2 Testing for Selectivity using Bivariate Probit}

To this juncture, the results point to the conclusion that central ownership is of dominant importance in the determination of soft budgets. This sub-section presents the results of a last attempt to examine the robustness of this conclusion under the use of alternative estimation methods. We focus on selection effects on central ownership exclusively, estimating a maximum likelihood model under the assumption that there are no such effects on the local ownership variables. ${ }^{13}$ We follow the methodology of Evans and Schwab (1995). ${ }^{14}$

To apply this methodology, we convert pertinent variables to binary ones. Thus, Cend equals 1 when Ceno is positive and zero otherwise, which does not entail a large loss of information since Ceno has $80 \%$ of its observations at zero and a further $12 \%$ close to 51 . Similarly, Softd equals 1 when Soft is positive and zero otherwise. Again, the loss of information is muted since $73 \%$ of the observations on Soft are zero.

To formulate the model to be estimated, assume that $C_{i}^{*}$ is a latent variable measuring the net benefits to decision-makers of keeping some central ownership in enterprise i. Cend is unity when $\mathrm{C}_{i}^{*}>$ 0 and zero otherwise. Then:

$$
C_{i}^{*}=Z_{i} \theta+\eta_{i}
$$

where $Z_{i}$ and $\eta_{i}$ are as defined in the previous section. Similarly, a modified form of equation (1) is:

$$
Y_{i}^{*}=X_{i} \beta+\text { Cend }_{i} \delta+\epsilon_{i}
$$

\footnotetext{
15. This assumption allows the use of bivariate probit avoiding the apparently insurmountable problems of higher-order probits.

14. Thanks to William Evans for use of software.
} 
(The variables Loco and Regd are assumed included in $\mathrm{X}_{\mathrm{i}}$ in this analysis to emphasize that we are not considering their endogeneity.) If $Y_{\mathrm{i}}^{*} \leq \alpha_{0}$, then $\operatorname{Soft} d_{\mathrm{i}}=0$; otherwise $\operatorname{Soft} d_{\mathrm{i}}=1$. The error terms, $\eta_{\mathrm{i}}$ and $\epsilon_{\mathrm{i}}$ are assumed to have zero means, variances of 1 , and a covariance of $\rho$. If $\rho$ differs significantly from zero then there are unmeasured selection effects on central ownership that are pertinent to the determination of soft budgets.

The results are presented in Table 6. They are consistent with those of previous sections. The central ownership variable is highly significant. The regional ownership variable for Darhan is significant, but the local ownership variable is again insignificant.

Table 6 adds a further important item of information: the error terms in the two equations are highly correlated, but negatively so. The omitted variables that cause an enterprise to be selected into the state sector lead to a smaller probability of a soft budget for that enterprise. Therefore, when selection effects are not take into account, the effect of central ownership would probably be underestimated.

\section{Conclusion}

Let us first consider the question of the overall validity of conclusions based on the complete spectrum of the results presented above. Certainly, there is a set of assumptions that would formally invalidate each set of results. For example, judgement on which variables are non-significant in Table 3 might be erroneous because of the ownership selection effects clearly identified in Table 6 . Or, the estimates in Table 5 might be questioned because of the decision to ignore the censored and categorical nature of the dependent variable. Or, one might doubt the treatment of local ownership in Table 4 because the instruments for this variable are weak. These are possibilities that cannot be rejected $a$ priori, because the information does not exist to test them.

Therefore, a final appraisal of the validity of the conclusions must rest on the reader's assessment of the plausibility of alternative assumptions that might invalidate our reading of the results. Our judgment is that it is highly unlikely that results would change if extra data were available to investigate the effects 
of alternative assumptions. This judgment rests on the consistency of the results across the differing estimation methods. The most plausible reason for such consistency is that each of the estimations is an approximation of the one that would be obtained were complete information available.

Which of the conclusions should be emphasized? The following are central to an understanding of the effects of privatization during the transition process:

1. Central ownership is of overwhelming importance in determining the presence of soft budgets.

2. Local ownership is of much less consequence. Local ownership varies in significance across regions and in a majority of regions does not lead to soft budgets.

3. One locality bucks the local trend, but that locality received a soft budget from the central government in the year preceding the observations reported here.

4. Very little else is important in explaining the presence of soft budgets. The only alternative hypothesis receiving consistent support is that of market concentration suggesting that an enterprise might be too big to fail on the national level. This result again stresses the importance of central over local policy.

One issue left unaddressed in this paper is whether our variable Soft really measures soft budgets or simply reflects enterprises' erroneous expectations of soft budgets. In a country where there are.close links between enterprise and government, where there is open access to higher levels of government, and where information flows freely, it is unlikely that such expectations are simply flights of fancy. Even if they were, erroneous expectations are important to economic events, since it is expectations of soft budgets that lead to the inefficient enterprise decisions that are the worst consequences of soft budgets. Hence, the dependent variable examined in this paper reflects an important element of reality however one resolves the ambiguity that is embodied in the paper's title. 


\section{References}

Alfandari, Fan, and Freinkman, "Government Financial Transfers to Industrial Enterprises and Restructuring," in Simon Commander, Qimiao Fan, and Mark Schaffer eds. Enterprise Restructuring and Economic Policy in Russia, EDI Development Studies, The World Bank, Washington D.C. 1996

Belka, Marek, Schaffer, Mark, Estrin, Saul, and Inderjit Singh, "Evidence from a Survey of StateOwned, Privatized, and Emerging Private Firms," Paper Presented at Workshop on Enterprise Adjustment in Eastern Europe, Transition Economics Division, The World Bank, September, 1994.

Boone, Peter "Grassroots Macroeconomic Reform in Mongolia," Journal of Comparative Economics, 18(3), June 1994, pages 314-28.

Boycko, Maxim, Andrei Shleifer, and Robert Vishny, "A Theory of Privatization," Economic Journal, March 1996, 106: 309-319.

Dewatripoint, Mathias, and Eric Maskin, "Credit and Efficiency in Centralized and Decentralized Economies," Review of Economic Studies, October 1995.

Evans, William and Robert Schwab, "Finishing High School and Starting College: Do Catholic Schools Make a Difference?" Quarterly Journal of Economics, November 1995, pp. 941-974.

Earle, John, Saul Estrin, and Larisa Leshchenko, "Ownership Structures, Patterns of Control, and Enterprise Behavior in Russia," in Simon Commander, Qimiao Fan, and Mark Schaffer eds. Enterprise Restructuring and Economic Policy in Russia, EDI Development Studies, The World Bank, Washington D.C. 1996 , pp. 205-249.

Earle, John, and Saul Estrin, "Worker Ownership in Transition" in Roman Frydman, Cheryl Gray, and Andrzej Rapaczynski eds. Corporate Governance in Central Europe and Russia: Volume 2 Insiders and the State. Budapest: Central European University Press, 1996.

Enkhbat, B. "Local Government Strengthening in Mongolia," Institute of Administration and Management Development, Ulaanbaatar, 1993.

Fan, Qimiao and Mark E. Schaffer. "Government Financial Transfers and Enterprise Adjustments in Russia, with Comparisons to Central and Eastern Europe." CEP Working Paper No. 394, The World Bank, Oct. 1993.

Government of Mongolia, "Law on the Government of Mongolia," Ulaanbaatar May, 1993.

Government of Mongolia, "Reform of Local Administration and Decentralization," Management Development Program of the Mongolian Government, April 1995.

Kornai, Janos, Economics of Shortage, North Holland: Amsterdam, 1980.

Kornai, Janos, "The Postsocialist Transition and the State: Reflections in the Light of Hungarian Fiscal Problems," American Economic Review, 82(2), pages 1-21, May 1992a. 
Kornai, Janos, The Socialist System: The Political Economy of Communism. Princeton University Press: Princeton, 1992b.

Kornai, Janos, "The Evolution of Financial Discipline under the Post-socialist System," Kyklos, 46(3), 1993, pages 315-36.

Korsun, Georges and Peter Murrell, "The Politics and Economics of Mongolia's Privatization Program," Asian Survey, XXXV, No. 5, May 1995: 472-486.

Korsun, Georges and Peter Murrell, "How Does the Transitional State Behave? Evidence from Retained State Ownership in Mongolian Privatization.” University of Maryland, 1996.

Li, David, "A Theory of the Soft Budget Constraint Based on Insiders' Control Rights," University of Michigan, 1996.

Murrell, Peter, Karen Turner Dunn, and Georges Korsun, "The Culture of Policy Making in the Transition from Socialism: Price Policy in Mongolia," Economic Development and Cultural Change, 1996.

Newey, Whitney K., "Generalized Method of Moments Specification Testing," Journal of Econometrics, 29, 229-256, 1985.

Oates, Wallace, and Robert Schwab, "Economic Competition Among Jurisdictions: Efficiency Enhancing or Distortion Inducing?" Journal of Public Economics, 35, pp. 333-354, 1988.

Pinto, Brian, Marek Belka and Stefan Krajewski, "Transforming State Enterprises in Poland: Evidence on Adjustment by Manufacturing Firms, "Brookings Papers on Economic Activity, 1993 (1), pp. 213 270.

Qian, Y. and C. Xu, "Why China's Economic Reforms Differ: The M-form hierarchy and entry/expansion of the non-state sector." Economics of Transition, 1(2), 135-170, 1993.

Qian, Yingyi and Gerard Roland, "Federalism and the Soft Budget Constraint," CEPR Research Paper, Stanford University, 1996.

Shleifer, Andrei, and Vishny, Robert W., "Politicians and Firms," Quarterly Journal Of Economics, November 1994.

State Statistical Office of Mongolia, Monthly Bulletin of Statistics, January 1996. Ulaanbaatar, 1996. 


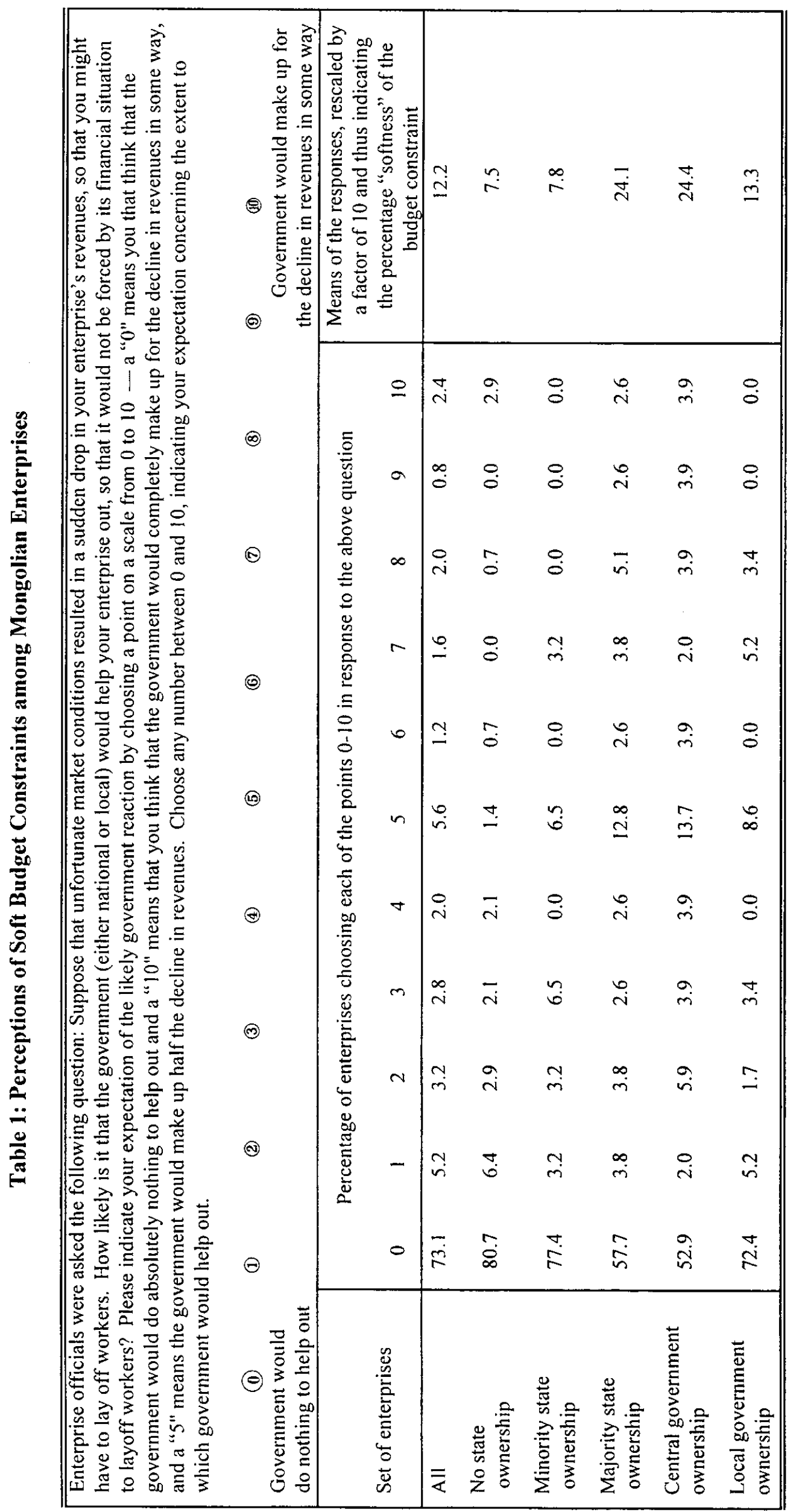




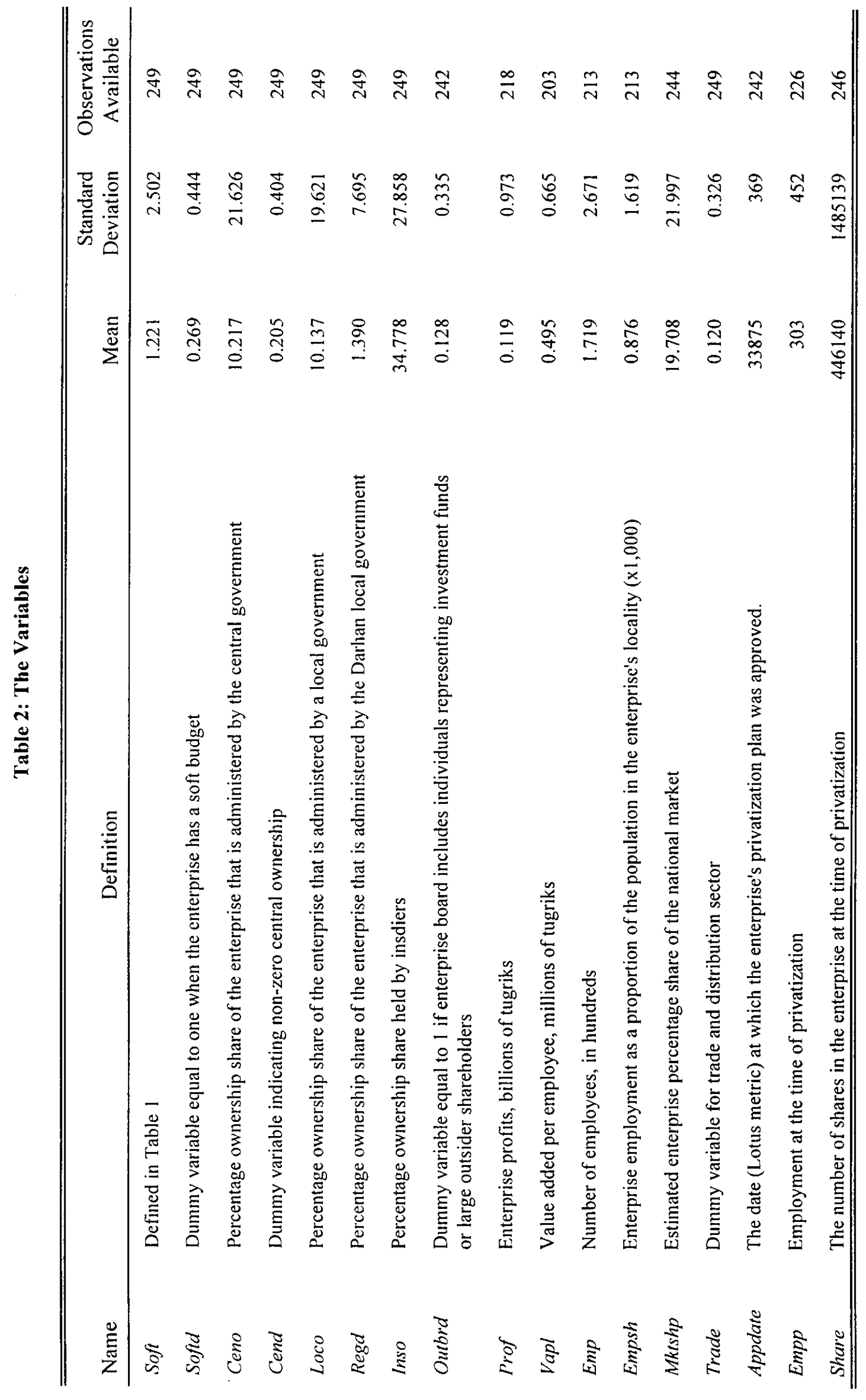

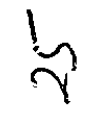




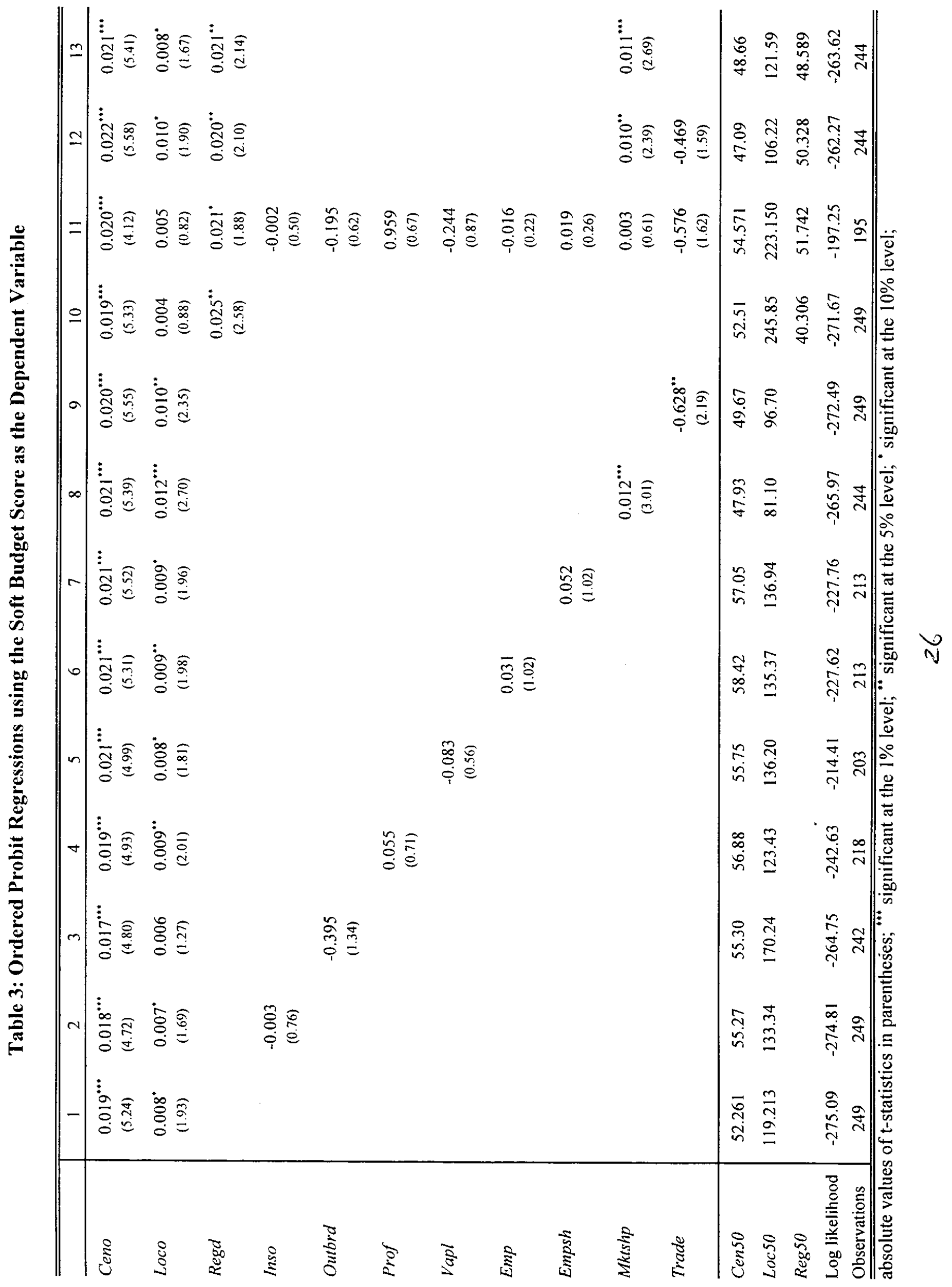




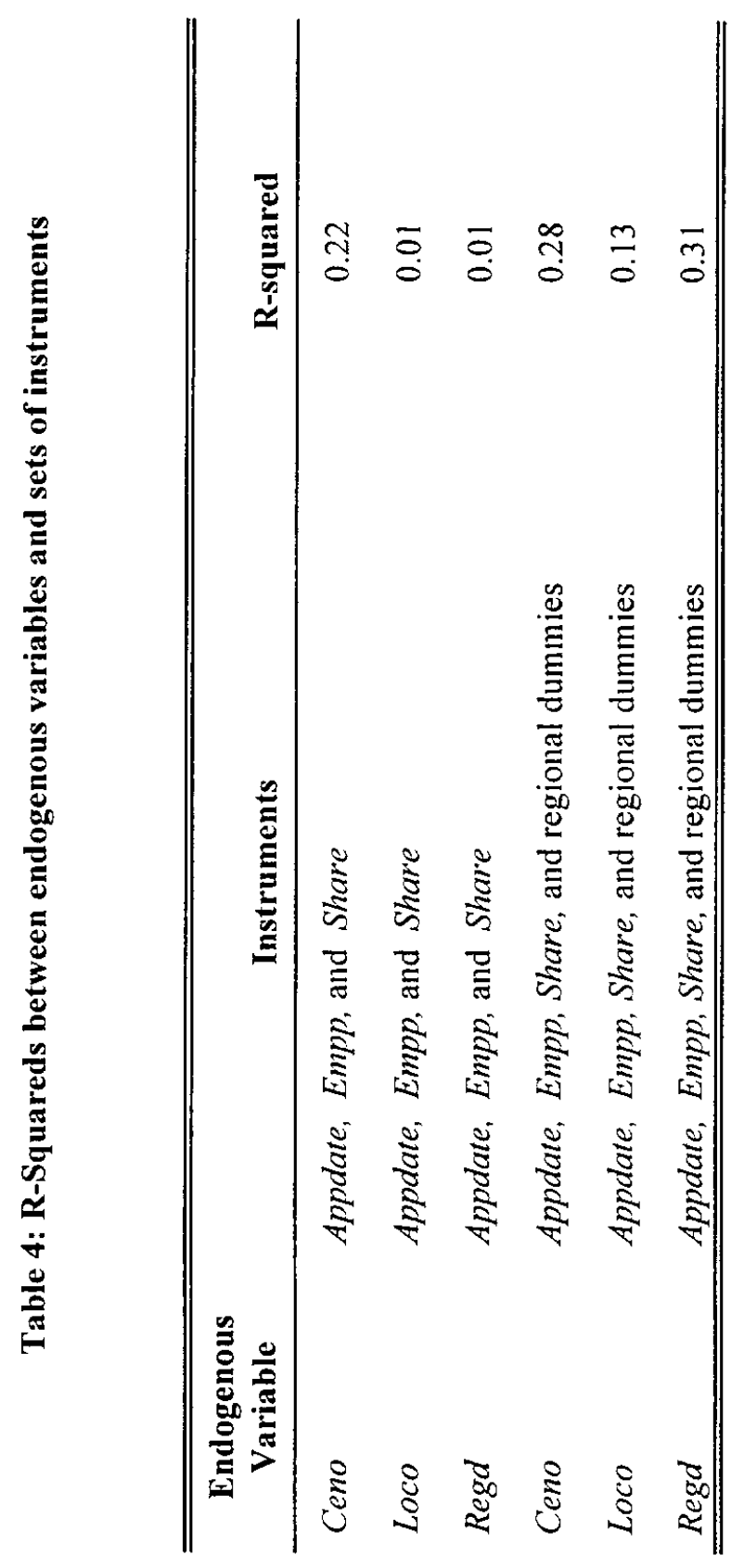

$x$
$n$ 


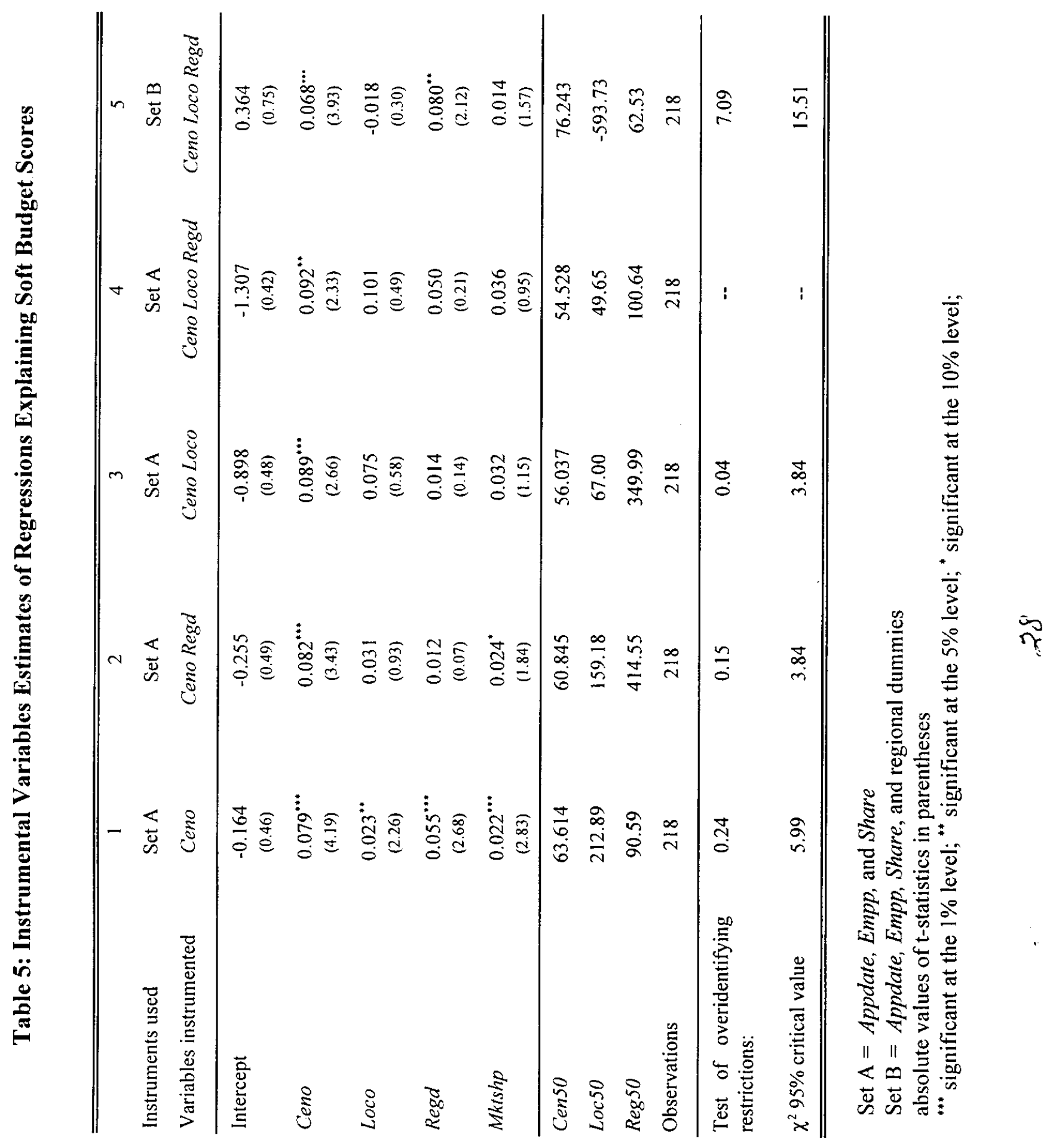




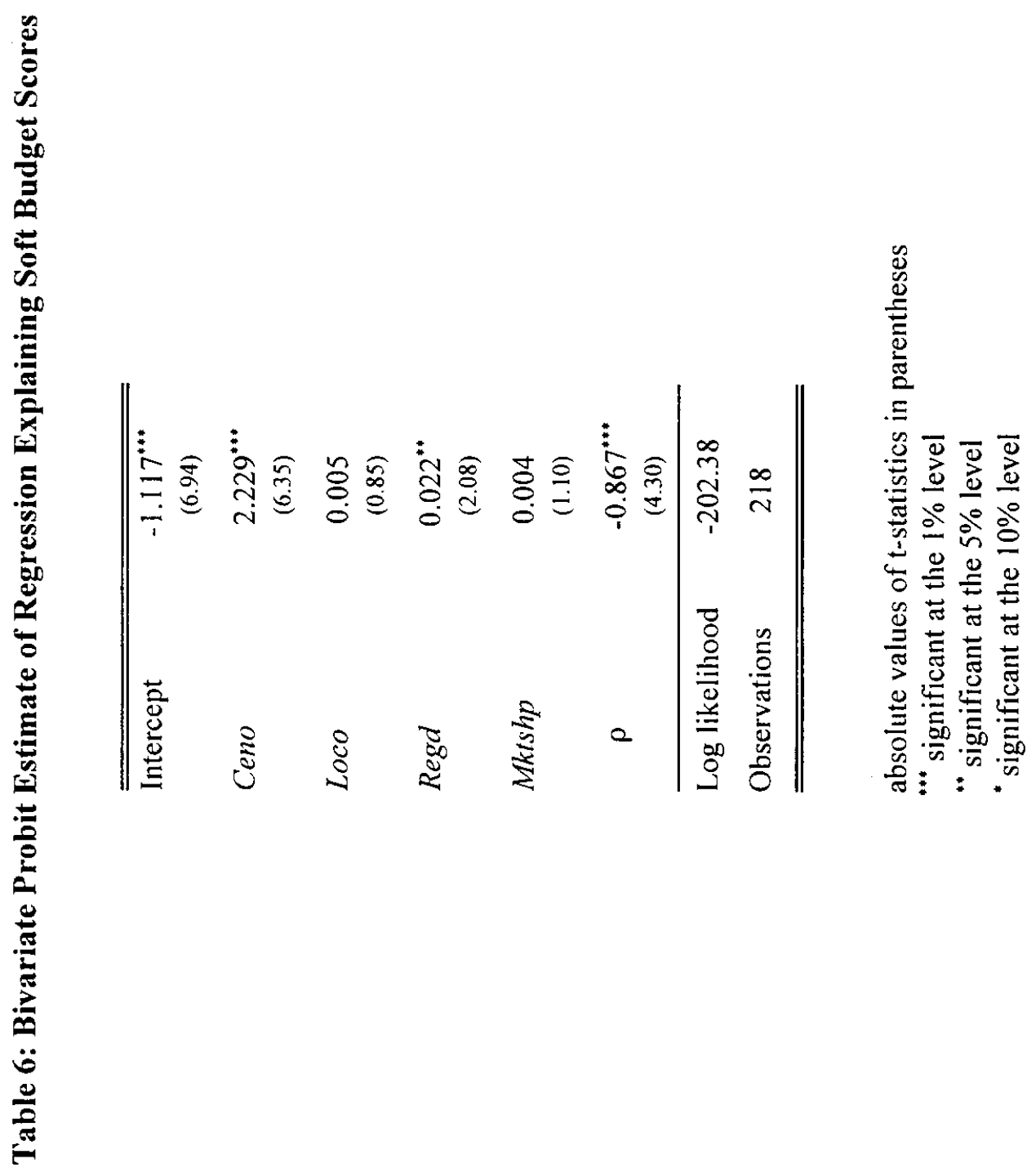

